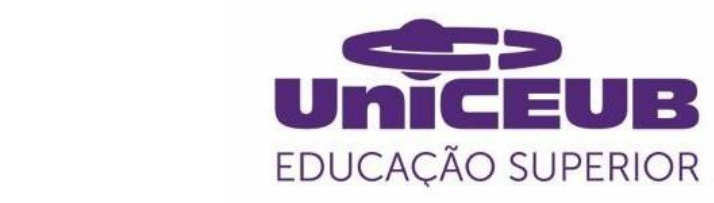

CENTRO UNIVERSITÁRIO DE BRASÍLIA- UnICEUB

PROGRAMA DE INICIAÇÃO CIENTÍFICA

EDUARDO JOSÉ FERREIRA SALES

THIAGO HENRIQUE QUEIROZ DE OLIVEIRA

A EFICÁCIA DO BLOQUEIO RADICULAR FORAMINAL NO ALÍVIO DA DOR CIÁTICA PELA HÉRNIA DISCAL LOMBAR: UM ESTUDO PROSPECTIVO, CONTROLADO, RANDOMIZADO E DUPLO-CEGO

BRASÍLIA 


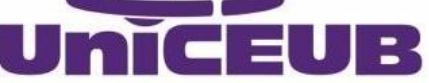 \\ EDUCAÇÃO SUPERIOR}

EDUARDO JOSÉ FERREIRA SALES

THIAGO HENRIQUE QUEIROZ DE OLIVEIRA

\section{A EFICÁCIA DO BLOQUEIO RADICULAR FORAMINAL NO ALÍVIO DA DOR CIÁTICA PELA HÉRNIA DISCAL LOMBAR: UM ESTUDO PROSPECTIVO, CONTROLADO, RANDOMIZADO E DUPLO-CEGO}

Relatório final de pesquisa de Iniciação

Científica apresentado à Assessoria de Pós-

Graduação e Pesquisa.

Orientação: Marcello Oliveira Barbosa

BRASÍLIA 


\section{DEDICATÓRIA}

Dedicamos esse projeto especialmente aos nossos pais, mães e irmãos, sem o apoio incondicional de vocês nada disso seria possível, amamos vocês. Às nossas namoradas por todo apoio nessa trajetória, nos auxiliando e dando forças mesmo quando

queríamos desistir. Por fim, dedicamos a todos aqueles que de alguma forma vem sofrendo com as repercussões que a pandemia está nos impondo. 


\section{AGRADECIMENTOS}

Agradecemos ao Dr. Marcello Oliveira Barbosa a oportunidade de prosseguir com essa rica e desafiadora experiência acadêmica. Ao nosso amigo Dr. Ângelo Santana Guerra nosso agradecimento por ter iniciado o projeto e nos indicado para sua continuidade. 


\section{EPÍGRAFE}

"Acreditar na medicina seria a suprema loucura se não acreditar nela não fosse uma maior ainda, pois desse acumular de erros, com o tempo, resultaram algumas verdades."

Marcel Proust 


\section{RESUMO}

Objetivo: avaliar o perfil clínico, a melhora da dor e a necessidade de intervenções cirúrgicas em pacientes submetidos ao bloqueio transforaminal com uso de corticosteroides e anestésicos. Métodos: ensaio clínico randomizado e duplo-cego, com $\mathrm{n}=45$, apresentando dor radicular unilateral em membros inferiores, tendo diagnóstico de hérnia discal lombar em único segmento. Ocorreu distribuição aleatória dos pacientes em dois grupos: o grupo intervenção e o grupo controle. Após, foram realizados bloqueios transforaminais com bupivacaína, dexametasona e clonidina no grupo intervenção, e no controle foi realizado o bloqueio com água destilada e bupivacaína. Além disso, foi aplicado o questionário de incapacidade de Oswestry no dia do procedimento e após uma e três semanas. Resultados: foram avaliados 45 pacientes, sendo 24 mulheres $(53,4 \%)$ e 21 homens (46,6\%). Dos pacientes que possuíam ocupação, 85,71\% ( $n=30)$ estavam afastados de suas funções por conta da doença e $14,29 \%(n=5)$ continuavam a trabalhar, porém, referindo limitações. Avaliou-se que os pacientes que foram submetidos a bloqueio transforaminal com injeção de corticoide, clonidina e anestésico apresentam alívio imediato, mas após três semanas, esse efeito não perdura de forma tão satisfatória tendo apenas $52 \%$ dos pacientes apresentando melhora em graus variados. Já no grupo controle, houve discreto alívio álgico após uma semana, que não perdurou de forma satisfatória após três semanas, com $50 \%$ dos pacientes evoluindo para melhora em graus variados. Discussão: os resultados desse estudo sugerem um efeito positivo após uma e três semanas do bloqueio foraminal tanto com a solução contendo corticoide, clonidina e anestésico quanto com a solução contendo água destilada e anestésico. Esse resultado favorece a possibilidade de que a melhora nas primeiras semanas está relacionada ao uso de anestésico na solução e não ao uso do corticoide. Conclusões: Novos estudos com um espaço amostral maior, novos dados epidemiológicos e um seguimento mais prolongado serão necessários para validar as hipóteses aventadas.

Palavras-Chave: Hérnia de disco lombar. Bloqueio foraminal. Dor ciática. 


\section{SUMÁRIO}

INTRODUÇÃO

FUNDAMENTAÇÃO TEÓRICA

MÉTODO 16

RESULTADOS E DISCUSSÃO 20

CONSIDERAÇÕES FINAIS

REFERÊNCIAS 29

ANEXOS 33 


\section{INTRODUÇÃO}

A dor crônica, uma sensação dolorosa com duração de alguns meses, é considerada um dos grandes problemas de saúde pública da atualidade e pode ser ou não associada a trauma ou doença e persistir mesmo após a lesão inicial ter cicatrizado ${ }^{1}$. Essa condição gera uma crescente demanda por serviços públicos de saúde devido à sua necessidade de tratamentos prolongados que abrangem diversas especialidades na área da saúde, além de gerar um grande impacto financeiro para a saúde pública².

O atual envelhecimento da população acarreta um aumento da prevalência de doenças crônicas e degenerativas e, consequentemente, de maior incidência de dor e incapacidade. Em muitos desses casos, a dor crônica é a principal queixa, fato que interfere de modo acentuado na qualidade de vida dos pacientes ${ }^{2,3}$.

Nesse contexto, se insere a dor lombar, um dos problemas de saúde mais comuns em adultos, que é definida como dor e desconforto localizados abaixo do rebordo costal e acima da linha glútea superior, com ou sem dor referida no membro inferior, sendo crônica se persistir por mais de três meses ${ }^{1}$.

Dentre as alterações degenerativas da coluna lombar, a hérnia discal é o principal diagnóstico, sendo também uma das principais condições que geram dor crônica atualmente, uma das maiores causas de auxílio-doença no Brasil, a maior causa de aposentadoria por invalidez e a que mais leva à intervenção cirúrgica, segundo dados do INSS de $2019^{4-6}$. Sua etiologia é multifatorial, estando relacionada com profissões com esforço físico e com altas cargas horárias de trabalho ${ }^{7}$, e apesar de ser descrita nas mais variadas faixas etárias, a hérnia discal ocorre principalmente entre a terceira e a quinta décadas de vida, sendo a média de idade do primeiro episódio agudo por volta de 37 anos. Estima-se que $2 \%$ a $3 \%$ da população tenham diagnóstico de hérnia de disco lombar, com prevalência em pessoas acima de 35 anos de 4,8\% em homens e 2,5\% em mulheres ${ }^{4,5,7,8}$. 
A hérnia discal é uma situação na qual ocorre o deslocamento do núcleo pulposo, conteúdo do disco intervertebral, devido a um rompimento do anel fibroso, geralmente em sua região posterolateral $\left.\right|^{3,4,8-10}$. Suas manifestações clínicas dependerão do volume de material herniado e sua relação com o diâmetro do canal medular devido à compressão e irritação das raízes lombares e do saco dural. A sintomatologia da doença é caracterizada por uma lombalgia inicial, que pode evoluir, em geral, após uma semana, para uma dor radicular ou lombociatalgia, que acompanha o dermátomo correspondente à raiz comprometida, irradiando para as nádegas ou parte posterior da coxa e é exacerbada com o movimento da coluna lombar, e, finalmente, persiste como ciática pura ${ }^{3-5,8,11}$.

No entanto, devido à grande variedade de manifestações clínicas com apresentação aguda ou crônica, deve-se estar atento a formas atípicas de apresentação e preparado para fazer um acurado diagnóstico diferencial, já que as causas de dor lombar são diversas e envolvem também causas não mecânicas como: inflamatórias, infecciosas, metabólicas e psicossomáticas ${ }^{5}$.

Nesse contexto, um exame físico adequado é essencial para o diagnóstico, podendo inclusive, através de cuidadosa avaliação dos dermátomos e miótomos, determinar o espaço vertebral em que está localizada a hérnia. Alguns testes específicos ajudam no diagnóstico, como o sinal de Lasègue, presente na compressão de raízes baixas ( $L 4$ a S1) e o teste de Nachlas de extensão do quadril, presente na compressão das raízes altas (L1 a L3), quando reproduzem ou aumentam o quadro doloroso. Exames de imagem também são fundamentais para o diagnóstico, localização, classificação e prognóstico da doença. $A$ ressonância magnética (RM) é considerada padrão-ouro para o diagnóstico, sendo indispensável para a correta avaliação do paciente, visto que permite a obtenção de informações detalhadas de partes ósseas e de tecidos moles que podem ajudar não só no diagnóstico correto, mas até na proposta terapêutica ${ }^{4,5}$.

Com relação à terapêutica, diversas técnicas são descritas na literatura, porém atualmente priorizam-se os procedimentos cirúrgicos minimamente invasivos, devido a menor agressão tecidual gerada, o menor tempo de internação, os menores riscos anestésicos e o retorno precoce às atividades laborais ${ }^{4,12}$. 
Os bloqueios transforaminal e epidural guiados por radioscopia são procedimentos amplamente empregados e consistem em boas opções entre as técnicas minimamente invasivas no tratamento da hérnia de disco lombar. Com a associação de contrastes radiopacos nas infiltrações, obteve-se maior precisão na localização da raiz nervosa. Por meio delas é possível reduzir a resposta inflamatória, melhorar o quadro álgico, reduzir o consumo de analgésicos, permitir o retorno mais rápido às atividades laborais e a diminuir a necessidade de intervenção cirúrgica nesses pacientes. No entanto, apesar do desenvolvimento e amplo emprego dessa técnica, existem muitas divergências a respeito da melhora clínica após a sua utilização associada a corticosteroides como modalidade terapêutica ${ }^{4,12,13}$.

Como exposto, a hérnia de disco lombar é um assunto de importante discussão para a saúde pública, e atualmente existe uma pequena base de dados na comunidade científica sobre os pacientes que foram submetidos às técnicas minimamente invasivas (especialmente o bloqueio transforaminal com corticosteroide) e necessitaram, posteriormente, de intervenção cirúrgica.

O objetivo deste trabalho é avaliar o perfil clínico, a melhora da dor e a necessidade de intervenções cirúrgicas em pacientes submetidos a essas técnicas minimamente invasivas, especialmente o bloqueio transforaminal com uso de corticosteroides. 


\section{FUNDAMENTAÇÃO TEÓRICA}

As dores lombar e ciática afetam a maioria da população em pelo menos um episódio durante a vida. Entretanto, a história natural da hérnia de disco lombar é favorável e em geral, há melhora espontânea dos sintomas ou após instituição de terapia conservadora ${ }^{14}$.

A hérnia de disco é causada pela ruptura completa do anel fibroso, com o subsequente extravasamento do conteúdo do centro do disco, o núcleo pulposo, para o canal vertebral $^{8-10}$. Parte do núcleo pulposo, placa terminal cartilaginosa, osso fragmentado ou tecido anular fragmentado são deslocados para fora do espaço discal ${ }^{10}$. Essas hérnias variam com relação à localização na coluna vertebral, podendo ser cervicais, torácicas, lombares e sacrais ${ }^{10}$.

Pondera-se que de 2 a $3 \%$ da população geral tenham diagnóstico de hérnia de disco lombar, atingindo principalmente indivíduos entre 30 e 50 anos. Estima-se que a prevalência, quanto à distribuição por sexo, seja de: 4,8\% em homens e $2,5 \%$ em mulheres, em relação à população geral. Ademais, representa o diagnóstico mais comum dentre as alterações degenerativas da coluna lombar e a principal causa de cirurgia da coluna $^{4,5,7,8}$.

Sobre a história natural da doença degenerativa discal, o processo degenerativo é divido em três estágios. O primeiro estágio é a disfunção, que é encontrado em indivíduos entre 15 e 45 anos, e é caracterizado por injúrias radiais e circunferenciais no anel fibroso discal e sinovite localizada nas articulações facetárias. O segundo é a instabilidade, ocorre em pessoas entre 35 e 70 anos e caracteriza-se por ruptura interna do disco, reabsorção progressiva do disco, degeneração das articulações facetárias com frouxidão capsular, subluxação e erosão articular. O estágio final, presente em pacientes com mais de 60 anos, é a estabilização, e nele o progressivo desenvolvimento de osso hipertrófico ao redor do disco e articulações facetárias levam ao enrijecimento segmentar ou anquilose franca. A hérnia de disco é considerada uma complicação da degeneração discal nos estágios de disfunção e instabilidade ${ }^{15}$. 
Evidências apontam para a participação da herança genética como componente importante na etiopatogênese da hérnia de disco, saindo do clássico envolvimento ambiental e do desgaste físico. Há diversos estudos buscando identificar genes que desempenham papel relevante no desenvolvimento e evolução dessa enfermidade ${ }^{16}$. Dentre os possíveis envolvidos parecem figurar o gene receptor da vitamina D (gene VDR), o gene que codifica para uma das cadeias polipeptídicas do colágeno IX (o gene COL9A2), genes dos colágenos I (COL1A1), XI (COL11A1), o gene "aggrecan" humano (AGC), responsável pela codificação do proteoglicano, maior componente proteico da cartilagem estrutural que suporta a função biomecânica nesse tecido e o polimorfismo de genes que codificam MMP3, IL1 e IL6 ${ }^{16}$.

Sabe-se que a dor na hérnia discal lombar resulta da soma de componentes mecânicos e inflamatórios, isso devido à herniação, degeneração do disco e da estenose foraminal ou do canal medular ${ }^{8}$. Com relação às manifestações clínicas da hérnia lombar, a dor lombar é a principal manifestação e envolve três tipos: a baixa, que é localizada entre o último arco costal e a prega glútea e de origem biomecânica; a lombociatalgia, que é irradiada da região lombar até um ou ambos os membros inferiores devido à irritação de raiz nervosa ou exacerbação de sintomas crônicos; e a ciática, uni ou bilateral, irradiada, na maioria das vezes, da raiz da coxa, atravessando o joelho, até o pé ipsilateral. Pode estar presente ou não o déficit sensitivo e/ou motor ${ }^{17}$.

O processo inflamatório e o fragmento do disco intervertebral herniado que comprime à raiz nervosa lombar geram a lombociatalgia, que piora ao permanecer sentado e/ou de pé por período prolongado ou após tosse e pode ser identificada pelo dermátomo correspondente à raiz nervosa envolvida ${ }^{18}$. A hérnia discal pode ser ainda comprimida pela hipertrofia facetária e pela presença de cistos facetários que ocupam o recesso lateral promovendo a compressão subarticular ou foraminal propriamente dita.

O quadro clínico típico de uma hérnia discal lombar tem como pedra angular a progressão da lombalgia inicial, que pode evoluir para uma lombociatalgia, apresentando-se como dores nos membros inferiores associadas ou não a manifestações neurológicas. Ao longo do tempo, em geral, após uma semana, a dor tende a persistir como dor ciática pura. 
Devido às vastas possibilidades etiológicas para dor lombar aguda ou crônica, os diagnósticos diferenciais devem sempre ser pesquisados, pois apesar de ser uma das principais causas de dor ciática, outras possibilidades como compressão tumoral, instabilidade, infecção e outras causas devem ser afastadas ${ }^{5,8,11}$. A sintomatologia da dor na hérnia lombar é decorrente da compressão da raiz nervosa no seu trajeto dentro do canal medular (na região central ou subarticular), no forâmen, ou na região extraforaminal. Quando a hérnia se direciona ao centro dos corpos vertebrais sem comprimir raízes nervosas, tende a ser assintomática. O quadro clínico pode mudar de acordo com a compressão ou não de estruturas adjacentes à herniação. O segmento lombar é um dos principais sítios de hérnia discal, localizando-se, mais frequentemente entre as vértebras $\mathrm{L} 5$ e $\mathrm{S} 1^{19}$.

Os pilares da investigação diagnóstica da dor lombar como um todo continuam sendo a história clínica e o exame físico, sendo as técnicas de imagem e outros exames apenas complementares ao diagnóstico ${ }^{4,5,20}$. Portanto, a indicação de exames de imagem deve estar baseada em um meticuloso exame clínico, tendo como objetivo apenas de adicionar informações não detectadas pelo exame físico e coleta de anamnese ${ }^{21}$.

A presença de ciática é um indicador de alto valor preditivo para hérnia de disco (sensibilidade de 0,95; especificidade de 0,88; valor preditivo positivo de 7,9 e valor preditivo negativo de 0,06$)$. Outro sinal altamente específico de hérnia de disco é o sinal de Lasègue que quando positivo tem a alta especificidade de 0,4 , porém com baixa sensibilidade. Tal sinal pode ser obtido mediante a elevação do membro inferior com o joelho estendido e o paciente em decúbito dorsal, sendo o principal teste realizado no exame físico tanto para diagnóstico quanto para avaliação da progressão ${ }^{20}$. Esse teste, popularmente conhecido como teste Lasègue, foi descrito inicialmente por Fort que descreveu o teste com a elevação do membro inferior com o joelho estendido enquanto o Ernest-Charles Lasègue descreveu o seu teste partindo da flexão para a extensão do joelho com o membro inferior elevado.

Outro elemento do exame físico que pode ser utilizado é o Sinal $X$, que consiste na conjugação da manobra de Valsalva com a flexão da coluna lombar antes a sua execução. Cecin HA, em estudo controlado mostrou que o sinal de Cecin (Sinal X) teve sensibilidade 
de $73,3 \%$ e $95,2 \%$ de especificidade para o diagnóstico das hérnias discais confirmadas pela RM. Na mesma amostragem, o sinal de Lasègue apresentou sensibilidade de $22,2 \% \mathrm{e}$ especificidade de $95,2 \%$ ( $P<0,001$ ), valor preditivo positivo de $90,9 \%$ e negativo de $36,4 \%$ $(P=0,153)$. Levando a concluir que o sinal de Cecin apresentou melhor desempenho diagnóstico do que o de Lasègue para o diagnóstico de hérnia discal lombar sintomática ${ }^{22}$.

Os exames de imagem carregam fundamental importância para diagnóstico, localização e prognóstico da hérnia discal lombar. A radiografia de coluna vertebral possui limitações no diagnóstico, porém é de grande importância para afastar possíveis comorbidades associadas. A tomografia computadorizada apresenta boa visualização da anatomia óssea, porém é inferior à Ressonância Magnética (RM) na visualização do disco intervertebral, podendo ser indicada para casos específicos de pacientes com estruturas metálicas internas ou claustrofóbicos ${ }^{23}$.

A combinação da capacidade de obtenção multiplanar das imagens e sequências especiais de pulso usadas nos exames da coluna vertebral faz da Ressonância Magnética (RM), nos dias atuais, o melhor método diagnóstico para avaliação da anatomia dos discos intervertebrais, nervos espinhais, saco dural, medula, cone medular, cauda equina e ligamentos da coluna vertebral. Na avaliação das hérnias discais lombares pela ressonância magnética é possível obter informações detalhadas dos ossos e de tecidos moles que podem ajudar não só no diagnóstico correto, mas também na proposta terapêutica que fazem da RM o exame indispensável para a correta avaliação do paciente ${ }^{4,5,24,25}$.

De acordo com sua apresentação morfológica na RM, a hérnia poderá ser classificada conforme a forma de deslocamento do núcleo pulposo em relação aos limites intervertebrais, sendo: protrusão quando, em um corte axial, a distância da altura da herniação é menor que a distância da base da região herniada em qualquer um dos planos; extrusão quando a distância da base herniada é menor do que a altura da hérnia; sequestro quando há descontinuidade entre o material herniado e o disco intervertebral ${ }^{5}$.

No que diz respeito às modalidades de tratamento descritas na literatura, o tratamento conservador e as técnicas minimamente invasivas tem sido usados como escolha inicial 
para tratar hérnias discais lombares em cerca de $90 \%$ dos pacientes que apresentam compressão radicular. A finalidade do tratamento é aliviar a dor, estimular a recuperação neurológica, com retorno precoce às atividades da vida diária e ao trabalho. A história natural da hérnia discal lombar é a diminuição e reabsorção do fragmento herniado do disco intervertebral pelo organismo o que geralmente ocorre após quatro meses do seu aparecimento. Pacientes com hérnias sequestradas, jovens, com leve déficit neurológico, hérnias pequenas, pouca degeneração discal, seriam os que melhor se beneficiariam do tratamento conservador. A crise de ciática pode ser tão severa a ponto de incapacitar o paciente e, nesse momento, o tratamento deve reduzir gradativamente a dor e aumentar a atividade física, evitando o repouso absoluto. O tratamento conservador inclui fisioterapia de apoio com analgesia e relaxamento, principalmente através de exercícios e alongamentos. O uso de estimulação elétrica nas suas formas mais variadas (TENS) não apresenta nenhuma evidência que justifique sua utilização; os estudos publicados mostram que não há fundamentos importantes estabelecendo o seu valor ${ }^{5}$. Tratando-se de técnicas minimamente invasivas, os bloqueios epidural e transforaminal são as abordagens bastante utilizadas no manejo da dor por infiltração de fármaco. Trata-se de uma infiltração de corticosteroide com solução fisiológica ou anestésico local no espaço epidural ou através do forâmen diretamente nas raízes nervosas ${ }^{26,27}$.

O tratamento cirúrgico da hérnia lombar possui indicações absolutas bem definidas, como a síndrome da cauda equina e paresias progressivas importantes ${ }^{28}$. A abordagem cirúrgica no tratamento da hérnia lombar não complicada, visando principalmente o manejo da dor, possui indicação relativa, devendo ser avaliada a possibilidade de um manejo menos agressivo. A discectomia tradicional ainda é bastante utilizada, contudo, a microdiscectomia vem apresentando resultados cada vez melhores por ser menos invasiva e possuir menores taxas de complicações nos dez anos seguintes de seguimento além de possuir menor tempo cirúrgico e sangramento reduzido durante o procedimento. O que se estuda hoje em dia é a vantagem de procedimentos minimamente invasivos ou percutâneos sobre a microdiscectomia ${ }^{4,5,12}$. 


\section{MÉTODO}

Foram avaliados no estudo, de novembro de 2018 a abril de 2020, 45 pacientes com dor radicular unilateral nos membros inferiores, todos estes com resultados de ressonância magnética lombar evidenciando hérnia discal lombar em apenas um segmento, por meio de estudo prospectivo, randomizado e duplo-cego. Todos os pacientes assinaram o Termo de Consentimento Livre Esclarecido, contendo os riscos e benefícios da terapia instituída. Dessa forma, por meio de lançamento de moedas os pacientes foram alocados em dois grupos: "cara" para os pacientes do grupo 1 (intervenção) e "coroa" para pacientes do grupo 2 (controle). O trabalho foi aprovado pelo Comitê Nacional de Ética e Pesquisa (CONEP) sob o número 3.104.615/18 - disponível na Plataforma Brasil.

Os critérios de exclusão incluíam a presença de outras enfermidades que possuem apresentação álgica semelhante à da hérnia lombar, como a bursite trocantérica, e/ou tendinite glúteas, coxartrose, pacientes oncológicos com tumoração em região lombar e/ou infecção com compressão radicular relacionada e litíase renal documentada. Foram excluídos também, pacientes que faziam uso de anticoagulantes e antiagregantes plaquetários, pacientes que já tivessem realizado bloqueio foraminal e/ou epidural nos últimos três anos e pacientes já submetidos a procedimento cirúrgico discal prévio como microdiscectomia, discectomia aberta ou artrodese.

Quanto à técnica realizada, o paciente era posicionado em decúbito ventral horizontal sem apoio no abdômen e quadris, os joelhos estendidos e com parâmetros vitais monitorizados. Era realizada a antissepsia e a assepsia, a colocação de campos estéreis e posteriormente, fazia-se a anestesia local com lidocaína a $2 \%$ sem vasoconstrictor e punção guiada pela radioscopia. Primeiramente, o nível lombar que seria infiltrado era determinado com realização da incidência anteroposterior absoluta. A incidência descrita por Ferguson, de angulação cranial da radioscopia, foi usada quando adequado de acordo com o nível lombar, principalmente no nível L5-S1. Ao visualizar a placa terminal como uma linha única, sem duplo contorno e os paralelismos dos platôs vertebrais do segmento a ser abordado, o radioscópio era rodado para o lado acometido, gerando uma imagem obliqua do lado acometido. O posicionamento do paciente era mantido e a angulação no 
plano craniocaudal com relação à angulação era anotado pelo técnico em radioscopia. Usava-se a agulha apoiada sob a região lombar do paciente para estabelecer o ponto exato de entrada da agulha, utilizando-se, assim, a sua ponta como referência que era mobilizada até coincidir exatamente com o forâmen intervertebral no seu terço superior (Figura I). Após estabelecimento do alvo, uma infiltração local do ponto de entrada com lidocaína 2\% sem vasoconstrictor era realizada. A agulha espinhal 22 Gauge com 3,5 polegadas com ponta de Quincke era introduzida segundo a técnica da visão em túnel e observada como um único ponto ao seguir o mesmo trajeto na incidência na radioscopia.

Figura I - Agulha posicionada no terço superior do forâmen intervertebral, visualizada na radioscopia.

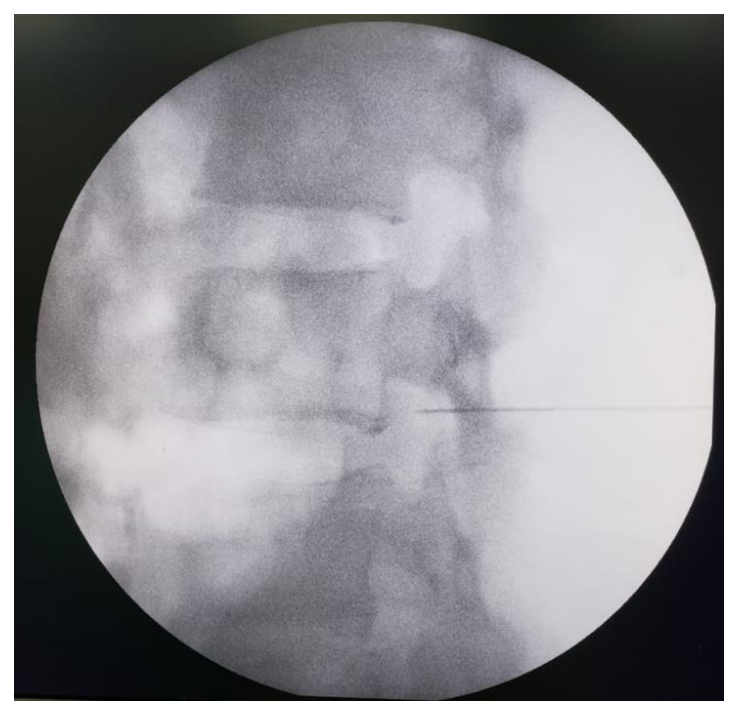

À medida que a agulha era introduzida a posição da radioscopia era alterada para fornecer a incidência do perfil absoluto para que a profundidade da agulha pudesse ser controlada. Conforme a agulha se aproximava da porção superior do forâmen intervertebral, o radioscópio retornava para a posição anteroposterior. O contraste era injetado sob visão contínua da radioscopia para acompanhar a distribuição deste na borda medial do pedículo e assegurar a infiltração adequada na bainha nervosa da raiz correspondente (Figura II).

Ao obter uma distribuição adequada e boa delimitação anatômica pelo contraste, injetava-se a solução. Ao final do procedimento, os pacientes eram encaminhados para a 
recuperação pós-anestésica e permanecia em observação por aproximadamente 30 minutos. Nenhuma medicação era prescrita após o procedimento.

Figura II - Raiz nervosa delineada por contraste, visualizada na radioscopia.

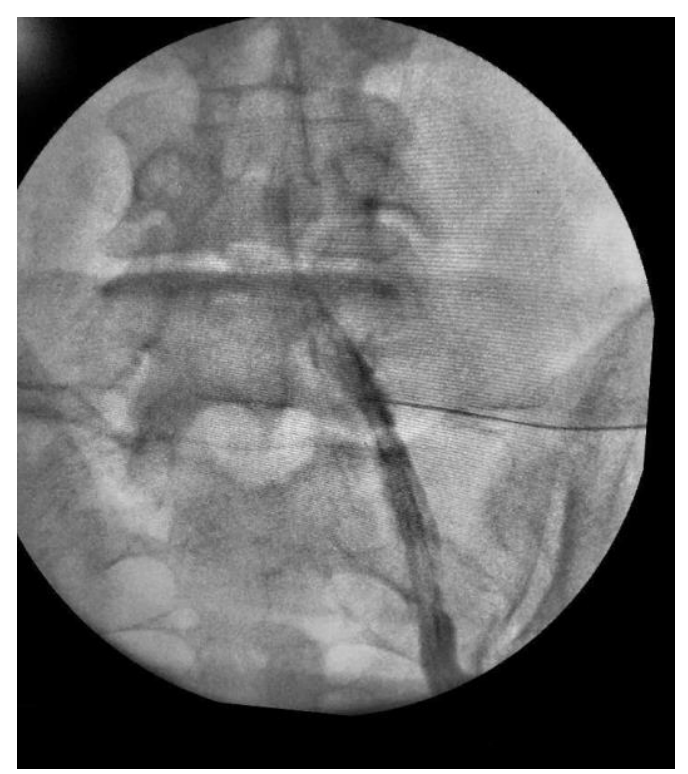

As soluções utilizadas para os bloqueios no grupo 1 (intervenção) eram compostas de: 01 (um) $\mathrm{mL}$ do anestésico local bupivacaína a 0,5\%, misturado a 02 (dois) $\mathrm{mL}$ de dexametasona $10 \mathrm{mg} / 2,5 \mathrm{~mL}$ e 01 (um) $\mathrm{mL}$ de clonidina $150 \mathrm{mcg} / \mathrm{mL}$. Nos pacientes do grupo 2 (controle) os bloqueios foram realizados com: 03 (três) $\mathrm{mL}$ de água destilada e 01 (um) $\mathrm{mL}$ de bupivacaína a $0,5 \%$.

Trata-se de um estudo duplo-cego, ou seja, médicos e pacientes não sabiam qual das soluções seriam utilizadas para o bloqueio. Os fármacos e a água destilada são transparentes, inclusive quando administradas na mesma seringa. Todos os bloqueios foram realizados em salas do centro cirúrgico do Hospital Regional do Paranoá (HRPa), centro de referência em coluna do DF, usando agulha de raquianestesia de $22 \mathrm{G} \times 10 \mathrm{~cm}$ e o intensificador de imagens para determinar o correto posicionamento da agulha no forame intervertebral. Cada seringa foi preparada por um pesquisador externo, de acordo com a randomização por meio de lançamento de moedas e entregue ao médico responsável pelo procedimento sem que ele tomasse conhecimento do conteúdo a ser injetado. 
Com intenção de quantificar os graus de variação clínica de cada paciente, foi aplicado um questionário simplificado de incapacidade de Oswestry (Anexo A), traduzido para o português, em três momentos para cada um dos pacientes: pré-bloqueio (Q1), uma semana após o bloqueio (Q2) e três semanas após o bloqueio (Q3). O questionário consiste em 10 perguntas graduadas de 0 a 5 pontos. As dez perguntas eram referentes a intensidade da dor, cuidados pessoais, capacidade de carregar peso, capacidade de se locomover, capacidade de manter-se em uma posição por um tempo determinado, alterações do sono, vida sexual, social e incapacidade de realizar viagens. A pontuação de cada paciente foi convertida para porcentagem, sendo que quanto mais próximo de $100 \%$, isto é 50 pontos, maior a incapacidade do paciente, e quanto mais próxima de $0 \%$, isto é zero pontos, menor a incapacidade do paciente.

Foram reunidas informações gerais, tais como idade, sexo, tratamentos clínicos adjuvantes realizados previamente, raiz nervosa bloqueada, ocupação, influência da doença na ocupação e por fim, a necessidade ou não de intervenção cirúrgica após a realização do bloqueio.

Os dados obtidos na pesquisa foram compilados e dispostos de maneira expositiva, com comparação intra e intergrupos. Ademais, os resultados foram comparados aos disponíveis em outros estudos de desenho semelhante. 


\section{RESULTADOS E DISCUSSÃO}

\section{Resultados}

O espaço amostral da pesquisa consiste em 45 pacientes, sendo composto por 24 mulheres $(53,4 \%)$ e 21 homens $(46,6 \%)$. A média de idade feminina foi de 51,1 anos $( \pm 10,65)$ ao passo que a média de idade masculina foi de 49,1 anos $( \pm 9,75)$. O grupo intervenção foi composto por 25 pacientes sendo sua maioria constituído por mulheres (60\%; $n=15)$ com uma média de idade de 52,2 anos $( \pm 10,8)$. Já o grupo controle possui 20 pacientes sendo $55 \%$ do sexo masculino $(n=11)$ com média de idade de 50,4 anos $( \pm 8,8)$ (Tabela I).

Tabela I - Dados demográficos.

\begin{tabular}{llll}
\hline & Intervenção $(n=25)$ & Controle $(n=20)$ & Total $(n=45)$ \\
\hline Idade & $51,25( \pm 10,25)$ & $48,8( \pm 10,38)$ & $50,23( \pm 10,31)$ \\
Sexo & & & \\
Masculino & $10(40 \%)$ & $11(55 \%)$ & $21(46,7 \%)$ \\
Feminino & $15(60 \%)$ & $9(45 \%)$ & $24(53,3 \%)$ \\
\hline
\end{tabular}

Quanto às ocupações (Tabela II), 77,78\% dos pacientes $(n=35)$ possuíam alguma função laboral, e 8,89\% $(n=4)$ já haviam se aposentado antes de apresentarem quadro típico de compressão radicular lombar. Dos pacientes que possuíam ocupação, 85,71\% ( $n=30)$ estavam afastados de suas funções por conta da doença e 14,29\% ( $n=5)$ continuavam a trabalhar, porém, referindo limitações. Apenas seis pacientes não referiam atividades remuneradas. As profissões mais prevalentes foram: empregada doméstica $(22,9 \%)$ e pedreiro/servente $(17,1 \%)$.

Tabela II - Dados ocupacionais.

\begin{tabular}{lll}
\hline Ocupação & Total $(n=35)$ & Afastados $(n=30)$ \\
\hline Empregada Doméstica & 8 & 7 \\
Pedreiro/Servente & 6 & 6 \\
Serviços gerais & 5 & 4 \\
Comerciante & 4 & 1
\end{tabular}




\begin{tabular}{lll} 
Eletricista & 2 & 2 \\
Administrativo & 2 & 2 \\
Professor & 2 & 2 \\
Lavanderia & 1 & 1 \\
Atendente & 1 & 1 \\
Marmoraria & 1 & 1 \\
Carpinteiro & 1 & 1 \\
Técnico Enfermagem & 1 & 1 \\
Psicopedagogo & 1 & 1 \\
\hline
\end{tabular}

Tratando-se de tratamentos adjuvantes (Tabela III), 36 pacientes $(80 \%)$ fizeram uso de uma ou mais modalidades terapêuticas como: fisioterapia, hidroterapia e acupuntura. No grupo intervenção, 19 pacientes (76\%) fizeram uso de fisioterapia, 5 pacientes (25\%) fizeram uso de hidroterapia e 7 pacientes (28\%) passaram por procedimentos de acupuntura. Já no grupo controle, 15 pacientes (75\%) foram submetidos a procedimentos de fisioterapia, 5 pacientes (20\%) fizeram sessões de hidroterapia e 9 pacientes (45\%) acupuntura. Em nenhum dos casos as terapias adjuvantes surtiram alívio satisfatório e sustentado dos sintomas.

Tabela III - Tratamentos adjuvantes.

\begin{tabular}{llll}
\hline & Intervenção $(n=25)$ & Controle $(n=20)$ & Total $(n=45)$ \\
\hline Tratamento adjuvante & $20(80 \%)$ & $16(80 \%)$ & $36(80 \%)$ \\
Fisioterapia & $19(76 \%)$ & $15(75 \%)$ & $34(75,55 \%)$ \\
Hidroterapia & $5(25 \%)$ & $5(20 \%)$ & $10(22,22 \%)$ \\
Acupuntura & $7(28 \%)$ & $9(45 \%)$ & $16(35,55 \%)$ \\
\hline
\end{tabular}

O nível do bloqueio (Tabela IV) mais frequente na amostra como um todo foi de L5-S1, totalizando 24 pacientes (53,3\%), seguido de L4-L5 (40\%) e L3-L4 (6,7\%). No geral, o lado predominante foi o direito $(64,4 \%)$. No grupo controle houve predomínio do nível L5-S1 com $50 \%$ dos bloqueios e do lado direito (75\%). No grupo intervenção houve predomínio similar, com o nível L5-S1 representando $56 \%$ da amostra e o lado direito com $56 \%$ dos bloqueios. 
Tabela IV - Nível e lado do bloqueio.

\begin{tabular}{llll}
\hline & Intervenção $(n=25)$ & Controle $(n=20)$ & Total $(n=45)$ \\
\hline Raízes Nervosas & $2(8 \%)$ & $1(5 \%)$ & $3(6,7 \%)$ \\
L3 - L4 & $9(36 \%)$ & $9(45 \%)$ & $18(40 \%)$ \\
L4 -L5 & $14(56 \%)$ & $10(50 \%)$ & $24(53,3 \%)$ \\
L5 -S1 & & $5(25 \%)$ & $16(35,6 \%)$ \\
Lado Acometido & $11(44 \%)$ & $15(75 \%)$ & $29(64,4 \%)$ \\
Esquerdo & $14(56 \%)$ & &
\end{tabular}

Para melhor entendimento das situações de melhora e piora, os pacientes dos dois grupos, intervenção e controle, após pontuação e comparação dos questionários Q1, Q2 e Q3, foram divididos em grupos A, B, C e D de acordo com graus variados de melhora ou piora ao longo de uma ou três semanas após o bloqueio. O sinal de mais (+), precedendo a letra do grupo, foi usado para definir a melhora clínica e o sinal de menos (-), precedendo a letra do grupo, foi usado para definir a piora clínica. O grupo +A representa aqueles que obtiveram melhora perdendo mais de 20 pontos entre Q1 e Q2 ou Q3, ou seja, ao longo de uma ou três semanas após o bloqueio. Já grupo -A representa aqueles que somaram 20 pontos ao questionário, ou seja, obtiveram piora significativa dos sintomas ao longo de uma ou três semanas. Os demais grupos, quais sejam: $+B /-B ;+C /-C ;+D /-D$; seguem a mesma ordem. $\mathrm{O}$ grupo $\mathrm{B}$ engloba todos aqueles que obtiveram ganho ou perda entre 10 e 19 pontos; O grupo $C$ abrange os que obtiveram variação de 5 a 9 pontos; $O$ grupo $D$ é composto por pacientes que obtiveram melhora ou piora de 1 a 4 pontos. Em resumo, pacientes do grupo A possuem grandes variações entre a sintomatologia relatada no ato do bloqueio e em situações subsequentes. Os grupos B e C possuem variações moderadas e o grupo D varia muito pouco.

Gráfico I - Comparativo quantitativo dos pacientes que relataram melhora ou piora da dor uma semana após o bloqueio para o grupo intervenção (vermelho) e grupo controle (verde). 
10

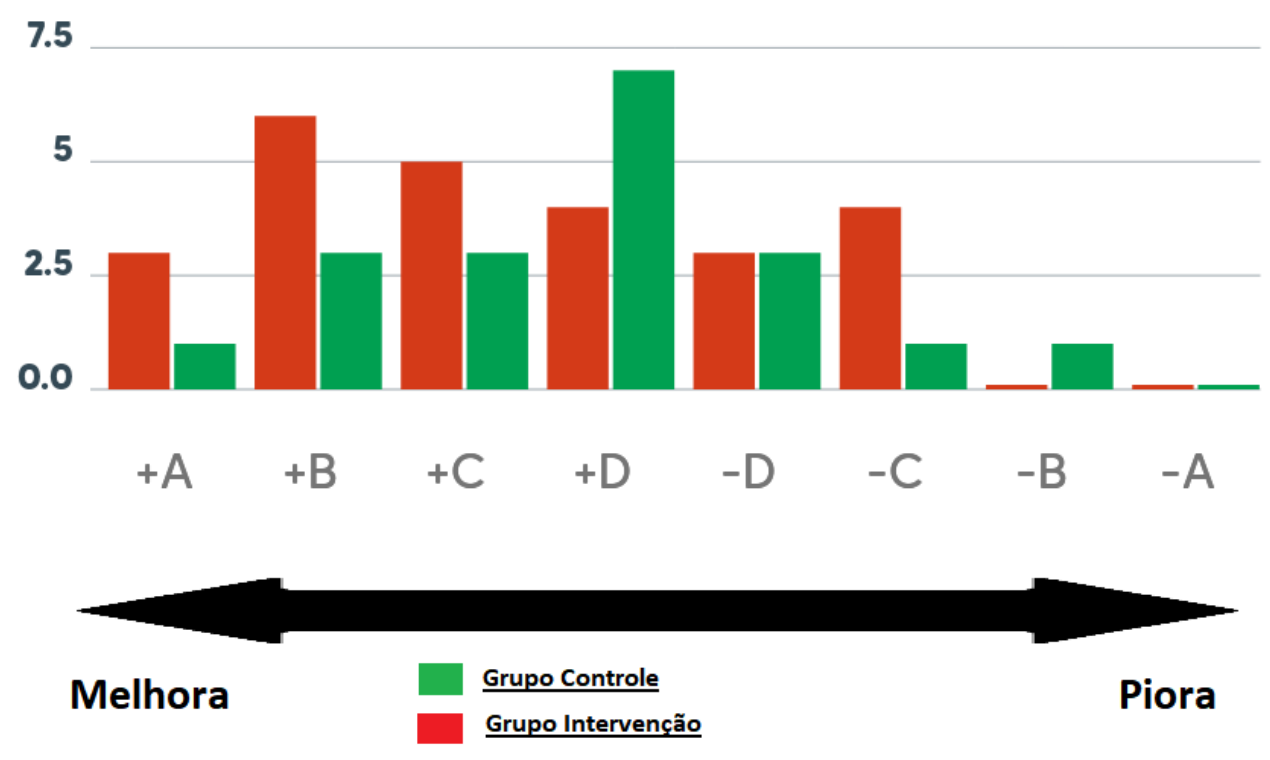

Tratando-se da avaliação da variação entre o questionário pré-bloqueio e o questionário uma semana após o procedimento, o gráfico I mostra que: o grupo intervenção apresentou três pacientes (12\%) enquadrados no grupo +A, seis pacientes (24\%) no grupo $+B$; cinco pacientes $(20 \%)$ no grupo $+C$ e quatro pacientes (16\%) no grupo $+D$. Quanto aos pacientes do grupo intervenção que obtiveram aumento do escore do questionário, refletindo piora clínica, temos três pacientes (12\%) no grupo -D; quatro pacientes (16\%) no grupo $-\mathrm{C}$ e nenhum paciente enquadrado nos grupos $-\mathrm{B}$ e -A.

Quanto aos pacientes sorteados para o grupo controle, tivemos um paciente (5\%) enquadrado no grupo $+A$; três pacientes $(15 \%)$ no grupo $+B$, três pacientes $(15 \%)$ no grupo $+C$ e sete pacientes (35\%) no grupo +D. Os pacientes do grupo controle que evoluíram com piora dos sintomas ao longo da primeira semana apresentaram-se assim: três pacientes (15\%) no grupo -D; um paciente $(5 \%)$ no grupo $-C$; um paciente $(5 \%)$ no grupo -B e nenhum paciente no grupo -A. Um paciente (5\%) não apresentou variação entre Q1 e Q2. 
Gráfico II - Comparativo quantitativo dos pacientes que relataram melhora ou piora da dor três semanas após o bloqueio para o grupo intervenção (vermelho) e grupo controle (verde).

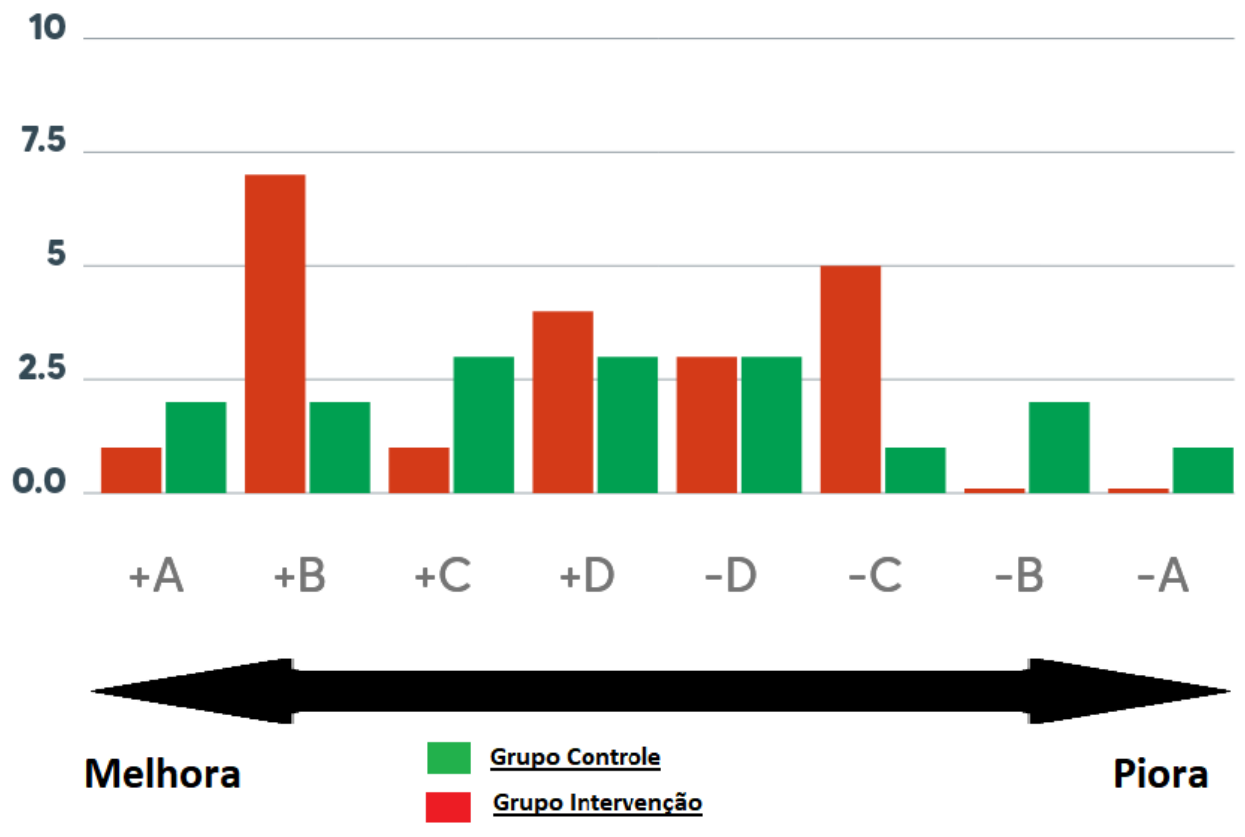

O gráfico II representa uma análise comparativa entre o questionário pré-bloqueio e o mesmo questionário aplicado três semanas após o procedimento. No grupo intervenção, ao final de três semanas, um paciente $(4 \%)$ foi enquadrado no grupo $+A$; sete pacientes $(28 \%)$ no grupo $+B$; um paciente $(4 \%)$ no grupo $+C$ e quatro pacientes $(16 \%)$ no grupo $+D$. Dos pacientes do grupo intervenção que evoluíram com piora da dor e limitação, temos: três pacientes (12\%) no grupo -D; cinco pacientes (20\%) no grupo $-\mathrm{C}$ e nenhum paciente nos grupos -B e -A. Quatro pacientes (16\%) não apresentaram variação entre Q1 e Q3 ao final de três semanas. No total, $52 \%$ dos pacientes do grupo intervenção evoluíram com melhora em graus variados.

O grupo controle três semanas após o bloqueio apresentou dois pacientes (10\%) no grupo $+A$; dois pacientes $(10 \%)$ no grupo $+B$; três pacientes $(15 \%)$ no grupo $+C$ e três pacientes (15\%) no grupo +D. Os que evoluíram com piora clínica temos: três pacientes (15\%) no grupo -D; um paciente (5\%) no grupo $-C$; dois pacientes $(10 \%)$ no grupo $-B$ e um paciente 
(5\%) no grupo -A. Três pacientes (15\%) não apresentaram variação na pontuação do questionário. Ao todo, $50 \%$ do grupo controle evoluiu para melhora em graus variados.

Quanto às médias calculadas pelos resultados do índice de Oswestry na situação prébloqueio, no grupo intervenção a média foi de $61,68( \pm 10,4)$, ao passo que no grupo controle foi de $60,3( \pm 15,3)$. O gráfico III apresenta o comparativo.

Gráfico III - Comparação entre as médias pré-bloqueio, após 1 semana e após 3 semanas após bloqueio dos grupos controle e intervenção.

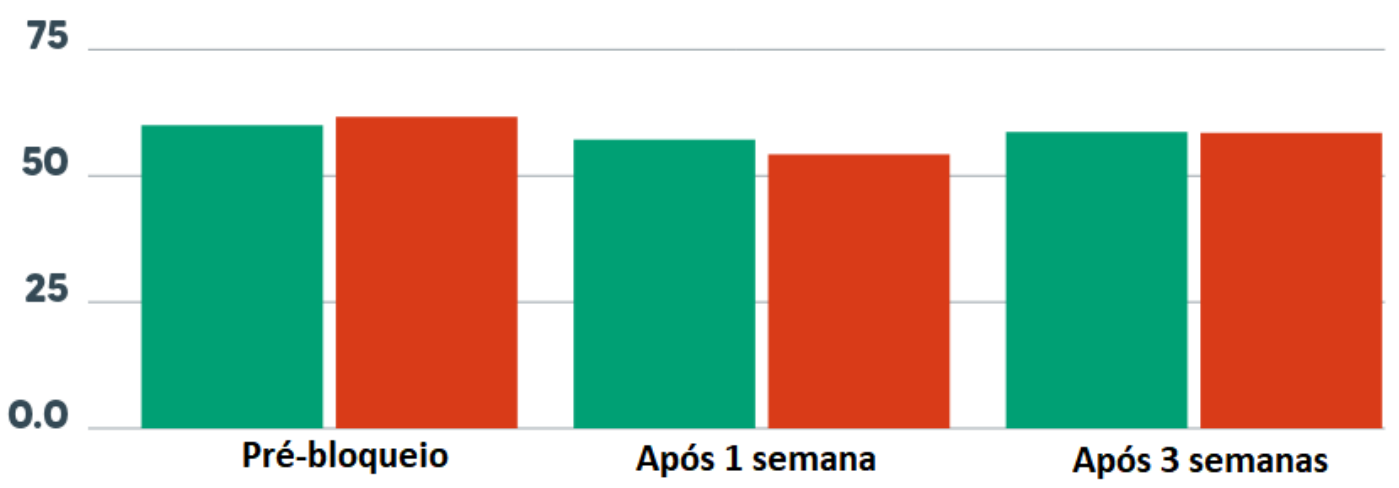

\section{Discussão}

A hérnia discal lombar é uma patologia mais prevalente em homens e ocorre principalmente entre a terceira e a quinta décadas de vida ${ }^{4,5,7,8}$. Na amostra do presente estudo observou-se idade média entre os participantes de 50,23 anos, e as mulheres $(53,3 \%)$ como a maioria dos acometidos por hérnia discal lombar. O parâmetro idade converge com o que há descrito em literatura, no entanto no trabalho foi evidenciado uma maioria de mulheres na amostra, podendo sugerir um perfil populacional para o espaço amostral. Em estudo de Souza et $a l^{13}{ }^{13}$, com $n$ de 61 pacientes, foi evidenciado uma maioria de mulheres $(55,7 \%)$ na realização do bloqueio transforaminal.

No trabalho de Cardoso et $a .^{29}$ sobre associação do diagnóstico clínico com a ocupação em um serviço de fisioterapia foi observado como grupo de maior prevalência de hérnia de disco, o grupo correspondente a serviços domésticos, assim como encontrado em nossa pesquisa. No entanto, o grupo construção civil não mostrou relação com o diagnóstico de hérnia de disco nesse trabalho, contudo, Daltaban et al. ${ }^{30}$, colocam 
trabalhadores da construção civil como uma das principais ocupações relacionadas com a hérnia discal lombar, convergindo com o exposto na nossa amostra. A localização mais comumente encontrada para a realização do procedimento L5-S1 $(53,3 \%)$ converge com dados coletados por Garcia et al. ${ }^{7}$. Vê-se a importância da questão ocupacional ligada às hérnias discais lombares, e assim, indicam que mais detalhes sobre as atividades laborais desses pacientes devem ser abordadas, como por exemplo, a carga horária de trabalho.

Neste estudo foi evidenciado que pacientes submetidos a bloqueio transforaminal com injeção de corticoide e anestésico apresentaram alívio imediato, mas que após três semanas, esse efeito não perdura de forma tão satisfatória, com o paciente não demonstrando melhora perceptível. Já no grupo controle, houve discreto alívio álgico após uma semana que não perdurou de forma satisfatória após 3 semanas. A comparação entre as médias dos dois grupos evidencia que não ocorreu resposta satisfatória em nenhum grupo.

Em estudo de Souza et al. ${ }^{13}$, foram realizados bloqueios foraminais em 61 pacientes sendo 32 pacientes com anestésico e corticoide e 29 apenas com solução salina. Nesse estudo observou-se melhora estatisticamente significativa do grupo que recebeu a medicação em relação ao grupo controle após uma semana pela escala de dor e após 3 meses quando utilizado o questionário de Oswestry. Ao compararmos nosso estudo, no grupo controle foi utilizado anestésico com água destilada e os pacientes obtiveram resposta semelhante ao grupo que recebeu corticoide, podemos inferir que essa melhora, na primeira semana, provavelmente ocorre pelo efeito do anestésico. A melhora observada após 3 meses no questionário de Oswestry indica que o período de seguimento da pesquisa deve ser estendido a pelo menos três meses para que tenhamos resultados mais precisos e comparáveis.

Manchikanti et al. ${ }^{31}$ em ensaio clínico duplo-cego envolvendo 120 pacientes com ciática unilateral realizou infiltração transforaminal com corticoide e anestésico em um dos grupos e anestésico e solução salina no outro grupo. Nos resultados publicados, pôde-se observar que ambos os grupos obtiveram melhora expressiva a curto e longo prazo. Esse resultado quando comparado ao do nosso trabalho, também favorece a possibilidade de 
que a melhora nas primeiras semanas está relacionada ao uso de anestésico na solução e não ao uso do corticoide. 


\section{CONSIDERAÇÕES FINAIS}

Os resultados desse estudo sugerem um efeito positivo após uma semana do bloqueio foraminal tanto com a solução contendo corticoide e anestésico quanto com a solução contendo água destilada e anestésico. Entretanto, após 3 semanas do procedimento, a solução contendo corticoide e anestésico não apresentou melhora efetiva, ao passo que os pacientes bloqueados com água destilada e anestésico continuaram a apresentar alguma melhora. É importante ressaltar que o quadro clínico da dor evocada pela compressão nervosa possui caráter autolimitado, podendo influenciar nas variações sintomáticas ao longo do tempo.

A pouca variação de melhora ao longo de três semanas após o bloqueio, 52\% no grupo intervenção e $50 \%$ no grupo controle, e a influência da resolubilidade espontânea e gradativa do quadro doloroso, reforça a ideia de que a solução empregada para bloqueio do grupo intervenção não apresenta grandes vantagens a longo prazo em relação à solução utilizada nos procedimentos do grupo controle.

Outros estudos com desenho semelhante a este apresentaram desfecho favorável ao grupo intervenção em curtos períodos, contudo estes estudos utilizaram apenas solução salina no grupo controle e, em sua grande maioria, não eram duplo-cegos, o que pode ter resultado no desfecho favorável do grupo intervenção em relação ao grupo controle. Aqueles estudos que apresentavam nos dois grupos o anestésico local evidenciaram uma resposta similar entre esses grupos, assim como pôde ser evidenciado nessa amostra.

O presente estudo apresenta algumas limitações como a reduzida amostra e o seguimento por período reduzido dos pacientes. Novos estudos com um espaço amostral maior, novos dados epidemiológicos e um seguimento mais prolongado serão necessários para validar as hipóteses aventadas. 


\section{REFERÊNCIAS}

1 - Almeida DC, Kraychete DC. Low back pain - a diagnostic approach. Rev dor [Internet]. 2017 Abr; 18(2): 173-177.

2 - Castro MC, Chaves ECL, Salgado SVH, Hollanda LD, Gama RCR, Silva PCM, et al. Impactos da dor crônica na vida das pessoas e a assistência de enfermagem no processo. Av. enferm. [Internet]. 2017 Abr; 35(1): 53-62.

3 - Nguyen TH, Lê QT. Outcomes of Lumbar Disc Herniation Treatment using Medication Method Coupled with Epidural Hydrocortisone Injection. J Orthop Sports Med [Internet] $2020 ; 2(1): 1-9$.

4 - Rezende R, Jacob Júnior C, Silva CK, Zanon IB, Cardoso IM, Batista Júnior JL. Comparison of the efficacy of transforaminal and interlaminar radicular block techniques for treating lumbar disk hernia. Rev. bras. ortop. [Internet]. 2015 Abr; 50(2): 220-225.

5 - Vialle LR, Vialle EN, Henao JES, Giraldo G. Hérnia discal lombar. Rev. bras. ortop. [Internet]. 2010; 45(1): 17-22.

6 - Ministério da Economia. Acompanhamento Mensal do Benefício Auxílio-Doença Previdenciário Concedido Segundo os Códigos da CID-10 - Janeiro a Dezembro de 2019. Brasília, DF, 2020.

7 - Garcia DKM, Vasconcelos TB, Cardoso ARNR, et al. Análise epidemiológica dos indivíduos com hérnias discais avaliadas pelo método de ressonância magnética. J. Health Biol Sci. 2018; 6(1):23-27.

8 - Carvalho LB, Oyakawa A, Martins RS, Castro PCG, Ferreira LMN, Melo JSA, et al. Hérnia de disco lombar: tratamento. Acta Fisiatr. 2013; 20(2):75-82. 
9 - Negrelli WF. Hérnia discal: procedimentos de tratamento. Acta ortop. bras. 2001; 9(4): $39-45$.

10 - Singh JR, Cardozo E, Christolias, GC. The clinical efficacy for two-level transforaminal epidural steroid injections. PMR Journal, 2017; 9(4): 377-382.

11 - Nunes RCS, Pontes ERJC, Costa IP. Evaluation of epidural blockade as therapy for patients with sciatica secondary to lumbar disc herniation. Rev. bras. ortop. [Internet]. 2016; 51(4): 424-430.

12 - Zanon IB, Jacob JC, Cardoso IM, Batista Júnior JL, Maia TC, Brazolino MA, et al. Comparison of the effectiveness of radicular blocking techniques in the treatment of lumbar disk hernia. Coluna/Columna 2015 Dez; 14(4): 295-298.

13 - Souza FFR, Nicolau RJ, Longo DM, Rodrigues LMR. Estudo clínico da eficácia do bloqueio anestésico radicular transforaminal no tratamento da radiculopatia lombar. Coluna/Columna 2011; 10(3): 234-238.

14 - Galucci M, Limbucci N, Zugaro, L, et al. Sciatica: treatment with intradiscal and intraforaminal injections of steroid and oxygen-ozone versus steroid only. Radiology: 2007 Mar; 242(3): 907-13.

15 - Azar, FM, Beaty JH, Canale ST. Campbell's Operative Orthopedics. 30. ed. Philadelphia: Elsevier, p. 1573-1726, 2017.

16 - Teles Filho RV, Abe GM, Daher MT. A influência genética na degeneração discal Revisão sistemática da literatura. Rev Bras Ortop 2020; 55(2): 131-138.

17 - Sousa FAEF, Colhado OCG. Bloqueio analgésico peridural lombar para tratamento de lombociatalgia discogênica: estudo clínico comparativo entre metilprednisolona e metilprednisolona associada à levobupivacaína. Revista Brasileira de Anestesiologia 2011; 61(5): 549-555. 
18 - Mostofi K, Khouzani RK. Preliminary results of lumbar disk herniation surgery by Endoscopic Destandau Method. J Clin Orthop Trauma 2018 Mar; 9(Suppl1): S149-S151.

19 - Almeida TRSH, Henrique MD, Moura MEL, et al. Hérnia de disco lombar: riscos e prevenção. Rev. Ciênc. Saúde Nova Esperança 2014, 12(2), 1-7.

20 - Cecin HA. Diretriz I: fundamentos do diagnóstico das doenças da coluna vertebral lombar. Ver. Bras. Reumatol. 2008, 48(Suppl 1): 3-7.

21 - Ribeiro-Rotta RF. Técnicas tomográficas aplicadas à Ortodontia: a evolução do diagnóstico por imagens. Rev. Dent. Press Ortodon. Ortop. Facial 2004; 9(5): 102-156.

22 - Cecin HA. Cecin's Sign ("X" Sign): improving the diagnosis of radicular compression by herniated lumbar disks. Rev. Bras. Reumatol. [Internet]. 2010 Feb [cited 2020 Oct 12] ; 50( 1 ): 44-55.

23 - Comunidades europeias. Directrizes para a Prescrição de Exames Imagiológicos. Luxemburgo: Serviço das Publicações Oficiais das Comunidades Europeias, p. 136, 2001.

24 - Nobrega Al. Tecnologia radiológica e diagnóstico por imagem. 1.ed. Difusão, 2012, v.03, p. 150-349, 2006.

25 - Minguetti G, Franco JHA, Ludwig VB. Avaliação das hérnias discais lombares pela ressonância magnética. Rev Bras Ortop. 1999; 34(4), 243-250.

26 - Zarghooni K, Beyer F, Siewe J, Eysel, P. The Orthotic Treatment of Acute and Chronic Disease of the Cervical and Lumbar Spine. Dtsch Arztebl Int. 2013; 110(44): 737-742.

27 - Legrand E, Bouvard B, Audran M, Fournier D, Valat JP. Sciatica from disk herniation: Medical treatment or surgery? Joint Bone Spine 2007;74(6): 530-535.

28 - Grasso G, Munakomi S, Sallì M. Red flag for cauda equina syndrome in symptomatic lumbar disc herniation. World Neurosurgery 2020;143: 232-234. 
29 - Cardoso VF, Pizzol RJ, Takamoto PM, Gobbo LA, Almeida AL. Associação do diagnóstico clínico com a situação ocupacional de usuários de um serviço de fisioterapia. Fisioter. Pesqui. 2017; 24(2): 169-175.

30 - Daltaban IS, Çetintepe SP, Ak H, Tutkun E. The Impact of Occupational Features on Radiological Staging of the Lumbar Disc Herniation. ACU Sağlık Bil Derg 2019; 10(3): 524528.

31 - Manchikanti L, Cash KA, Pampati V, Falco FJE. Transforaminal Epidural Injections in Chronic Lumbar Disc Herniation: A Randomized, Double-Blind, Active-Control Trial. Pain Physician 2014; 17:E489-E501 


\section{ANEXOS}

ANEXO A - Questionário Simplificado de Incapacidade de Oswestry

Seção 1: Intensidade da dor.

\begin{tabular}{|l|l|}
\hline & Sem dor no momento \\
\hline & A dor é leve nesse momento \\
\hline & A dor é moderada nesse momento \\
\hline & A dor é mais ou menos intensa nesse momento \\
\hline & A dor é muito forte nesse momento \\
\hline
\end{tabular}

Seção 2: Cuidados pessoais (Vestir-se, tomar banho etc)

\begin{tabular}{|l|l|}
\hline & Eu posso cuidar de mim sem provocar dor extra \\
\hline & Posso me cuidar mas me causa dor \\
\hline & É doloroso me cuidar e sou lento e cuidadoso \\
\hline & Preciso de alguma ajuda, mas dou conta de me cuidar \\
\hline & Preciso de ajuda em todos os aspectos para cuidar de mim \\
\hline & Eu não me visto, tomo banho com dificuldade e fico na cama. \\
\hline
\end{tabular}

\section{Seção 3: Pesos}

\begin{tabular}{|l|l|}
\hline & Posso levantar coisas pesadas sem causar dor extra \\
\hline & $\begin{array}{l}\text { A do levantar coisas pesadas sinto dor extra } \\
\text { posicionadas, e.g., numa mesa. }\end{array}$ \\
\hline & $\begin{array}{l}\text { A dor me impede de levantar coisas pesadas mas dou um jeito de levantar } \\
\text { coisas }\end{array}$ \\
\hline & leves ou pouco pesadas se estiverem bem posicionadas. \\
\hline & Só posso levantar coisas muito leve \\
\hline & Não posso levantar nem carregar nada. \\
\hline
\end{tabular}


Seção 4: Andar

\begin{tabular}{|l|l|}
\hline & A dor não me impede de andar (qualquer distância) \\
\hline & A dor me impede de andar mais que $2 \mathrm{Km}$ \\
\hline & A dor me impede de andar mais que ? $\mathrm{Km}$ \\
\hline & A dor me impede de andar mais que poucos metros \\
\hline Só posso andar com bengala ou muleta \\
\hline Fico na cama a maior parte do tempo e tenho que arrastar para o banheiro \\
\hline
\end{tabular}

Seção 5: Sentar

\begin{tabular}{|l|l|}
\hline & Posso sentar em qualquer tipo de cadeira pelo tempo que quiser \\
\hline & Posso sentar em minha cadeira favorita pelo tempo que quiser \\
\hline & A dor me impede de sentar por mais de 1 hora \\
\hline & A dor me impede de sentar por mais de ? hora \\
\hline & A dor me impede de sentar por mais que 10 minutos \\
\hline
\end{tabular}

Seção 6- De pé

\begin{tabular}{|l|l|}
\hline & Posso ficar de pé pelo tempo que quiser sem dor extra \\
\hline & Posso ficar de pé pelo tempo que quiser, mas sinto um pouco de dor \\
\hline & A dor me impede de ficar de pé por mais de $1 \mathrm{~h}$ \\
\hline & A dor me impede de ficar de pé por mais ? hora \\
\hline & A dor me impede de ficar de pé por mais de 10 minutos \\
\hline
\end{tabular}

\section{Seção 7: Sono}

\begin{tabular}{|l|l|}
\hline & Meu sono não é perturbado por dor \\
\hline & Algumas vezes meu sono é perturbado por dor \\
\hline & Por causa da dor durmo menos de 6 horas \\
\hline & Por causa da dor durmo menos de 4 horas \\
\hline & A dor me impede de dormir. \\
\hline
\end{tabular}


Seção 8: Vida sexual (se aplicável)

\begin{tabular}{|l|l|}
\hline & Minha vida sexual é normal e não me causa dor extra \\
\hline & Minha vida sexual é normal, mas me causa dor extra \\
\hline & Minha vida sexual é quase normal, mas é muito dolorosa \\
\hline & Minha vida sexual é muito restringida devido à dor \\
\hline & A dor me impede de ter atividade sexual. \\
\hline
\end{tabular}

Seção 9: vida social

\begin{tabular}{|l|l|}
\hline & Minha vida social é normal e eu não sinto dor extra \\
\hline & $\begin{array}{l}\text { Ainha vida social é normal, mas aumenta o grau de minha dor. } \\
\text { esforço, como esportes, etc }\end{array}$ \\
\hline & A dor restringiu minha vida social e eu não saio muito de casa \\
\hline A dor restringiu minha vida social a minha casa \\
\hline Não tenho vida social devido a minha dor
\end{tabular}

Seção 10: Viagens

\begin{tabular}{|l|l|}
\hline & Posso viajar para qualquer lugar sem dor. \\
\hline & Posso viajar para qualquer lugar, mas sinto dor extra \\
\hline & A dor é ruim, mas posso viajar por 2 horas \\
\hline & A dor restringe minhas viagens para distâncias menores que1 hora \\
\hline & A dor restringe minhas viagens para as necessárias e menores de 30 minutos \\
\hline & A dor me impede de viajar, exceto para ser tratado. \\
\hline
\end{tabular}

